\title{
High Photo-Current in Solution Processed Organic Solar Cells Based on Porphyrin Core A- $\pi-D-\pi-A$ as Electron Donor Material
}

\author{
Núria F. Montcada, ${ }^{a}$ Susana Arrechea, ${ }^{b}$ Agustín Molina-Ontoria, ${ }^{c}$ Ana I. Aljarilla, ${ }^{b}$ Pilar de la \\ Cruz, ${ }^{b}$ Luis Echegoyen, ${ }^{* c}$ Emilio Palomares ${ }^{*}{ }^{a, d}$ and Fernando Langa ${ }^{* b}$
}

Page 1 of 41 


\begin{abstract}
Two new conjugated acceptor-donor-acceptor (A- $\pi-\mathrm{D}-\pi-\mathrm{A})$ molecules with a porphyrin core linked by ethynylene bridges to two thiophene (1a) or thienylenevinylenethiophene (1b) units and both capped by N-ethylrhodanine have been synthesized. These compounds were used as the main electron donor moieties for bulk heterojunction small molecule organic solar cells (BHJSMOSC). The optimized devices, with PC71BM as the main electron acceptor molecule, show remarkable short circuit currents, up to $13.2 \mathrm{~mA} / \mathrm{cm}^{2}$, an open circuit voltage of around $0.85 \mathrm{~V}$, and power conversion efficiencies up to $4.3 \%$ under $100 \mathrm{~W} / \mathrm{cm}^{2}$. The External Quantum Efficiency (EQE), Atomic Force Microscopy (AFM), hole mobility, Photo-Induced Charge Extraction (PICE) and Photo-Induced Transient Photo-Voltage (PIT-PV) were analyzed in devices based on 1a and $1 \mathrm{~b}$ in order to account for differences in the final performance of the two molecules. The PIT-PV decays showed slower recombination kinetics for devices fabricated with 1b. Moreover, the EQE was greater for $\mathbf{1 b}$ and this is ascribed to the better nanomorphology, which allows better charge collection before carrier recombination takes place.
\end{abstract}




\section{Introduction}

Solution processed organic solar cells (OSCs) have improved significantly in recent decades,[14] due to the judicious design of push-pull low band-gap copolymers, optimization of the nanoscale morphologies of the photoactive layers and enhanced carrier mobility, all of which have led to power conversion efficiencies (PCEs) of 10\% for single-junction polymer solar cells (PSCs) $[5,6]$ and up to $11 \%$ for tandem PSCs.[7] Moreover, small molecule organic solar cells (SMOSCs) have emerged as complementary systems to the polymeric materials and they have undergone rapid development in recent years as SMOSCs offer potential advantages such as the possibility of obtaining better-defined molecular structures, easier purification and better batchto-batch reproducibility.[8,9] Indeed, power conversion efficiencies for bulk heterojunction small molecule organic solar cells (BHJ-SMOSCs) have exceeded 10\% and these are expected to be higher for tandem devices.[10-13]

Numerous different chemical architectures, especially as donor moieties, have been explored for SMOSCs [11, 14-19] and the most promising are the donor-acceptor (D-A) 'push-pull' molecules. Within this group, the use of porphyrin moieties (POR) as the main donor has recently been reported but this remains relatively unexplored.

Inspired by natural photosynthetic structures, such us chlorophylls, porphyrins and their derivatives, these excellent building blocks offer efficient light harvesting architectures, high stability, and their large and rigid planar structure allows fine tuning of their energetic and morphological properties.[20] For example, POR-based photosensitizers are among the best sensitizers in dye sensitized solar cells (DSSCs). In recent years, remarkable progress has been made on using POR as the main donor moieties[21-26] and efficiencies as high as $8 \%$ have been 
reached in SMOSC [27] devices while in DSSC systems efficiencies close to $12 \%$ have been described.[28]

Recently, we described two similar conjugated acceptor-donor-acceptor (A- $\pi$-D- $\pi$-A) compounds that also contained a Zn-porphyrin but were capped by dicyanovinylene groups as acceptor units - these materials gave a photoconversion efficiency (PCE) of 3.21\%.[29] With the aim of significantly improving the design and thus the performance of the final device, we report here: (a) the synthesis and characterization of two new conjugated POR-based acceptor-donoracceptor (A- $\pi-\mathrm{D}-\pi-\mathrm{A})$ 'push-pull' molecules 1a and 1b (Fig. 1); (b) the device fabrication and performance of these materials in solution-processed SMOSCs using PC71BM as the main electron acceptor moiety and (c) analysis of the carrier recombination kinetics. Compounds 1a and $\mathbf{1 b}$ were used as electron donor molecules in the blend, with the Zn-porphyrin core acting as a donor linked by ethynylene groups to one or two units of thienylenevinylene and capped by $\mathrm{N}$ ethylrhodanine as acceptor units. The strategy for this design is based on the use of the ethynylene units to make the system planar, the thienylenevinylene to extend the $\pi$-conjugation and the incorporation of hexyl chains on the thiophene units to enhance solubility. Finally, the use of rhodanine as the acceptor provides a stronger charge transfer character to the molecule and increases the light harvesting efficiency.

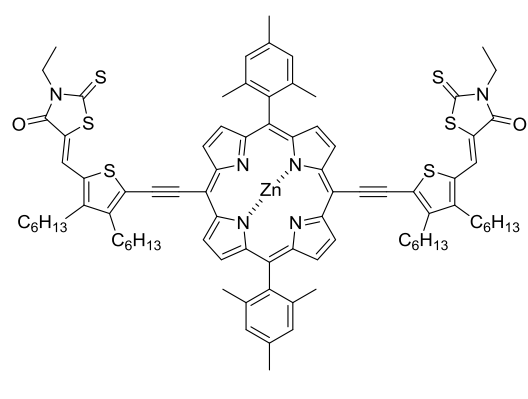

$1 a$

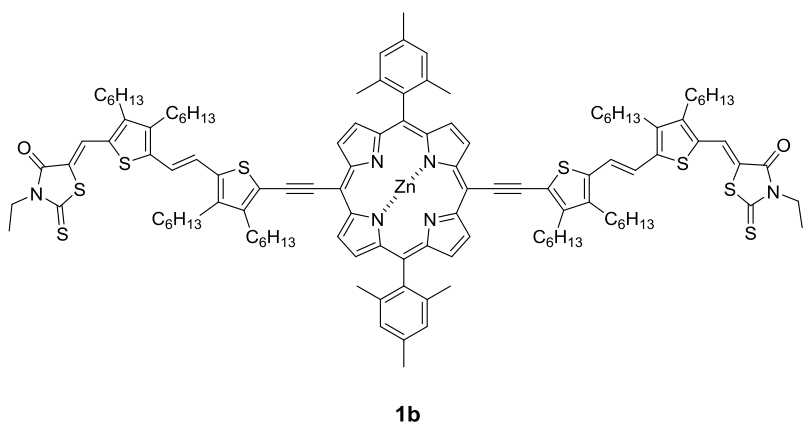

1b

Figure 1. Molecules 1a and $\mathbf{1 b}$. 


\section{Synthesis and Characterization}

Compounds 1a-b were obtained in $82 \%$ and $45 \%$ yield, respectively, by Knoevenagel condensation of $\mathbf{2} \mathbf{a}-\mathbf{b}[28]$ with N-ethylrhodanine and piperidine as base (Scheme 1). Both new compounds were satisfactorily characterized by ${ }^{1} \mathrm{H}$ and ${ }^{13} \mathrm{C}$ NMR, FT-IR and MALDI-MS (see Supporting Information for synthetic details and full analytical and spectroscopic data). In the ${ }^{1} \mathrm{H}$ NMR spectra of $\mathbf{1 a}$ and $\mathbf{1 b}$ a new signal was observed at $8.00 \mathrm{ppm}$ and $7.95 \mathrm{ppm}$, respectively, and this confirms the success of the condensation reaction. The mass spectrum of 1a showed the molecular ion peak at m/z $1498.75 \mathrm{amu}$ and $\mathbf{1 b}$ gave a molecular ion peak at m/z $2051.69 \mathrm{amu}$.

Compounds 1a-b showed excellent thermal stability up to $300{ }^{\circ} \mathrm{C}$, with $\mathrm{Td}$ values of $377^{\circ} \mathrm{C}$ and $355{ }^{\circ} \mathrm{C}$ for $\mathbf{1 a}$ and $\mathbf{1 b}$, respectively (Figure S9 and S10); this thermal stability is suitable for photovoltaic applications.

\section{Optical Properties}

The optical properties of $\mathbf{1 a}$ and $\mathbf{1 b}$ in $\mathrm{CH}_{2} \mathrm{Cl}_{2}$ (DCM) solutions and in thin films are shown in Fig. 2 and the characteristics of semiconductors $\mathbf{1 a}$ and $\mathbf{1 b}$ are collected in Table 1.

The absorption spectra in DCM solution of both compounds exhibit a panchromatic absorption in the visible region. Compound 1a shows the characteristic absorption pattern of a $\mathrm{Zn}$-chelated porphyrin with an intense Soret band (B band) at $507 \mathrm{~nm}(\log \varepsilon=5.27)$ and a broad intense intramolecular charge transfer (ICT) band with a maximum at $709 \mathrm{~nm}(\log \varepsilon=5.09)$. Extension of the conjugation on the bridge by the introduction of a new thienylenevinylene unit had a significant impact on the absorption spectrum of $\mathbf{1 b}$. This change led to a broader absorption, which is bathocromically shifted, for the Soret band to $547 \mathrm{~nm}(\log \varepsilon=5.02)$ and in the ICT band at $716 \mathrm{~nm}(\log \varepsilon=5.02)$. Comparison of the corresponding absorptions in films shows that 
the absorption bands became broader and red-shifted as a consequence of the closer intermolecular interactions in solution.

The fluorescence spectra of $\mathbf{1 a - b}$, measured in DCM $\left(\mathrm{CH}_{2} \mathrm{Cl}_{2}\right)$ and with excitation at 481 and $482 \mathrm{~nm}$, respectively, show emission bands at 727 and $746 \mathrm{~nm}$, respectively (Figure S13 and S14).

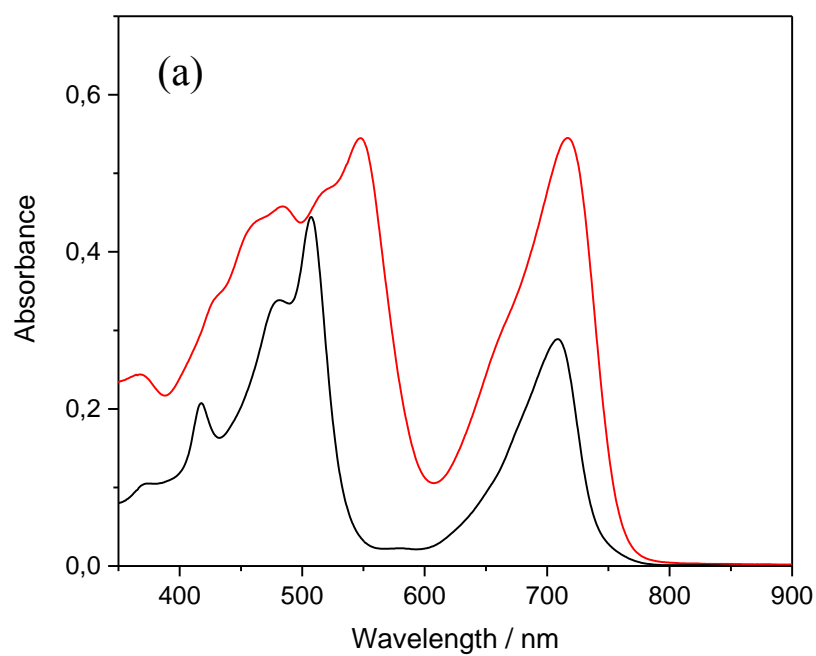




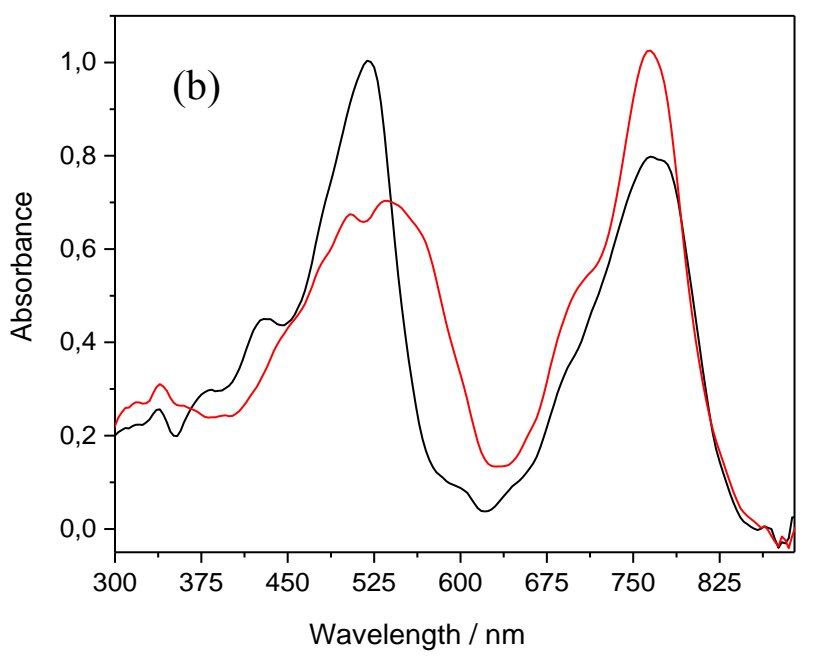

Figure 2. (a) UV-Visible spectra of 1a (black) and 1b (red) in DCM solution. (b) Normalized UV-Vis spectra of $\mathbf{1 a}$ (black) and $\mathbf{1 b}$ (red) and in thin films (red line).

From absorbance and emission data, the $\mathrm{E}_{0-0}$ values were calculated. The HOMO-LUMO gaps are as narrow as 1.74 and $1.69 \mathrm{eV}$ for $\mathbf{1 a}$ and $\mathbf{1 b}$, respectively. 
Table 1 UV-Vis, ${ }^{a}$ Fluorescence Emission ${ }^{\mathrm{a}}$ and $\mathrm{OSWV}^{\mathrm{b}}$ data for compounds $\mathbf{1 a - b}$

\begin{tabular}{|c|c|c|c|c|c|c|c|c|}
\hline & $\begin{array}{c}\lambda_{\max } \text { sol } \\
(\mathrm{nm})\end{array}$ & $\log (\varepsilon)$ & $\begin{array}{c}\lambda_{\max } \text { film } \\
(\mathrm{nm})\end{array}$ & $\begin{array}{c}\lambda_{\mathrm{em}} \\
(\mathrm{nm})\end{array}$ & $\begin{array}{l}E_{0-0}^{\mathrm{c}} \\
(\mathrm{eV})\end{array}$ & $\begin{array}{c}E_{\mathrm{ox}}^{l \mathrm{~b}, \mathrm{~d}} \\
(\mathrm{~V})\end{array}$ & $\begin{array}{c}E_{\text {НОMо }}{ }^{\mathrm{e}} \\
(\mathrm{eV})\end{array}$ & $\begin{array}{c}E_{\text {LUMO }} \\
(\mathrm{eV})\end{array}$ \\
\hline \multirow[t]{3}{*}{$1 \mathbf{a}$} & 481 & 5.16 & 435 & 727 & 1.74 & 0.26 & -5.36 & -3.62 \\
\hline & 507 & 5.27 & 522 & & & & & \\
\hline & 709 & 5.09 & 768 & & & & & \\
\hline \multirow[t]{3}{*}{$1 b$} & 482 & 4.95 & 510 & 746 & 1.69 & 0.14 & -5.24 & -3.55 \\
\hline & 547 & 5.02 & 540 & & & & & \\
\hline & 716 & 5.02 & 762 & & & & & \\
\hline \multicolumn{9}{|c|}{$\begin{array}{l}\text { a } 10^{-5} \mathrm{M} \text { in dichloromethane }(\mathrm{DCM}) ;{ }^{\mathrm{b}} 10^{-3} \mathrm{M} \text { in } o \text {-dichlorobenze }(\mathrm{ODCB}) \text {-acetonitrile }(4: 1) \text { versus } \mathrm{Fc} / \mathrm{Fc}^{+}\left(\mathrm{E}_{\mathrm{ox}}=\right. \\
0.04 \mathrm{~V}) \text { glassy carbon, Pt counter electrode, } 20{ }^{\circ} \mathrm{C}, 0.1 \mathrm{M} \mathrm{Bu}_{4} \mathrm{NClO}_{4} \text {, scan rate }=100 \mathrm{mV} \mathrm{s} \mathrm{s}^{-1} ;{ }^{\mathrm{c}} \text { estimated from the } \\
\text { intersection between the normalized absorption and normalized emission spectra at } \lambda_{\max } ;{ }^{\mathrm{d}} \text { reversible processes; } \\
\text { calculated with respect to ferrocene, } \mathrm{E}_{\mathrm{HOMO}}:-5.1 \mathrm{eV} \text {. }\end{array}$} \\
\hline
\end{tabular}

\section{Electrochemical Properties}

The electrochemical properties of $\mathbf{1 a}$ and $\mathbf{1 b}$ were investigated by Cyclic Voltammetry (CV) and Osteryoung Square Wave Voltammetry (OSWV) in $o$-dichlorobenze (ODCB)-acetonitrile (4:1)

(Table 1, Figures S15 and S16). On the cathodic side, both compounds showed a first reversible one-electron oxidation wave at $0.26 \mathrm{~V}$ for $1 \mathrm{a}$ and $0.14 \mathrm{~V}$ for $\mathbf{1 b}\left(\mathrm{vs} \mathrm{Fc} / \mathrm{Fc}^{+}\right.$in all cases). This first oxidation potential is ascribed to the oxidation of the porphyrin core; it can be remarked that the extended conjugation in $\mathbf{1 b}$ gives rise to a decrease in the $\mathrm{E}_{\mathrm{ox}}$ value by $12 \mathrm{mV}$ with respect to $\mathbf{1 a}$. A second reversible oxidation wave was observed at $0.65 \mathrm{~V}$ for $\mathbf{1 a}$ and at $0.42 \mathrm{~V}$ for $\mathbf{1 b}$, and this is attributed to the thienylenevinylene units. Compound $\mathbf{1 b}$ showed two more non-reversible oxidation waves at 0.63 and $0.88 \mathrm{~V}$, which are attributed to oxidation of the thienylenevinylene moieties. The estimated EHOMO values were determined to be $-5.36 \mathrm{eV}$ for $1 \mathrm{a}$ and $-5.24 \mathrm{eV}$ for $1 \mathbf{b .}$

Low-lying HOMO levels should result in high open-circuit voltages (Voc).[30-32] The E EumO values of 1a-b are higher than the $\mathrm{E}_{\mathrm{LUMO}}$ of PC71BM $(-4.0 \mathrm{eV})$, i.e., -3.62 and $-3.55 \mathrm{eV}$ for $1 \mathbf{a}$ 
and 1b, respectively. Hence, the LUMO energy levels of these small-molecules (Fig. 3) clearly match the LUMO of PC71BM, thus enhancing charge transfer.

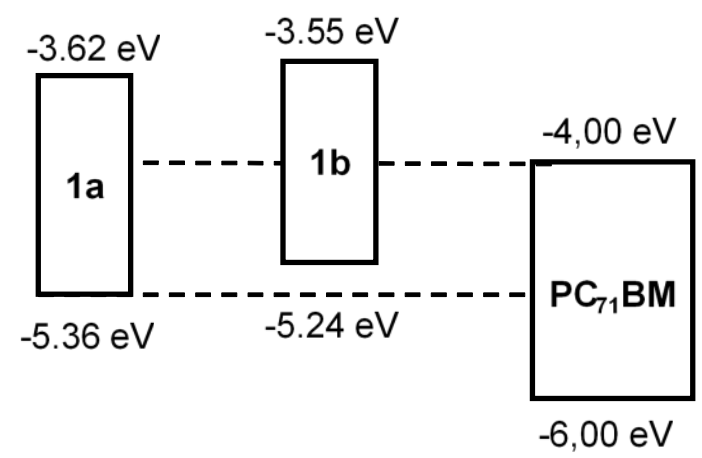

Figure 3. Schematic representation of the HOMO and LUMO energy levels for $\mathbf{1 a}, \mathbf{1 b}$ and PC71BM.

\section{Theoretical Calculations}

In order to gain an insight into the structure and the electronic properties of the materials, theoretical studies were carried out by performing density functional theory (DFT) calculations at the $\mathrm{B} 3 \mathrm{LYP} / 6-31 \mathrm{G}^{*}$ level in vacuo using Gaussian $03 \mathrm{~W}$.

The optimum geometries obtained for dyes $\mathbf{1 a}$ and $\mathbf{1 b}$ (Figure S17) show that the $\pi$-conjugated system, porphyrin macrocycle and the thienylenevinylene monomers are planar. The dihedral angles for this system are around $4^{\circ}$.

The calculated dihedral angle for the $N$-ethylrhodanine with the adjacent thiophene ring $(\theta)$ is around $1.5^{\circ}$. The planarity of the whole $\pi$-conjugated system is responsible for the extended conjugation and this situation is consistent with the calculated wavefunctions of the frontier molecular orbitals. 
The HOMO and LUMO are spread over the whole porphyrin and the corresponding thienylenvinylene system. Thus, both orbitals are overlapped and this promotes the HOMO to LUMO electronic transitions (Figure S18).

The theoretical HOMO-LUMO gaps are similar for both dyes, with a slightly lower value for compound $\mathbf{1 b}(1.72 \mathrm{eV})$ than for $\mathbf{1 a}(1.85 \mathrm{eV})$. These values are of the same order of magnitude as those determined by electrochemical measurements.

The greater extent of the conjugation in dye $\mathbf{1 b}$ results in an increase in the HOMO energy level and, as a consequence, a bathochromic shift in the maximum absorption wavelength, which in turn improves the light harvesting behavior.

The differences between the HOMO of the donor (1a or 1b) and the LUMO of the acceptor (PC71BM)[24] (1a: $1.12 \mathrm{eV}, \mathbf{1 b}: 0.86 \mathrm{eV})$ point to efficient Voc values. Furthermore, the difference between the LUMO of the dyes 1a and 1b and the LUMO of PC71BM (1a: $0.73 \mathrm{eV}$, 1b: $0.85 \mathrm{eV}$ ) ensures efficient exciton dissociation at the $\mathrm{D} / \mathrm{A}$ interface.

\section{Device Characterization}

The photovoltaic (PV) properties of $\mathbf{1 a}$ and $\mathbf{1 b}$ were investigated by fabricating solar cells using the conventional sandwich structure of ITO/poly(3,4-ethylenedioxythiophene): polystyrenesulfonate (PEDOT:PSS)/small-molecule:acceptor/Ca/Al. The fabrication method and other details are provided in the Supporting Information. The electrical characterization of all devices was performed under ambient conditions with AM $1.5 \mathrm{G}$ simulated illumination at an intensity of $100 \mathrm{~mW} \mathrm{~cm}^{-2}$. The current density-voltage characteristics and the external quantum efficiency (EQE) are shown in Fig. 4 and the performance parameters are summarized in Table 2 as a function of the donor:PC71BM weight ratios . Average values were taken from 12 devices. 
The devices based on a 1a:PC71BM blend film with a w/w ratio of 1:2 exhibited an average power conversion efficiency (PCE) above 3\%, with an open-circuit voltage (Voc) of $0.85 \mathrm{~V}$, high short-circuit current (Jsc) and poor FF of 30.8\% (Fig. 4a). On the other hand, the photovoltaic device with 1b:PC71BM at a blend ratio of 1:4 w/w showed a record PCE of 4.24\%, with Voc $0.8 \mathrm{~V}$, a Jsc of $13.2 \mathrm{~mA} / \mathrm{cm}^{2}$ and a FF of $40.1 \%$ (Fig. 4b). Moreover, the EQE values, which are displayed in Figures $4 \mathrm{c}$ and $4 \mathrm{~d}$, were measured under monochromatic light for 1a:PC71BM and 1b:PC71BM complete devices at different blend ratios. Both spectra exhibit a broad spectral response, ranging from 300 to $800 \mathrm{~nm}$, whereas the mixture of $1 \mathbf{b}: P C 71 \mathrm{BM}$ at a $1: 4 \mathrm{w} / \mathrm{w}$ ratio gave the highest incident photon-to-current efficiency $(80 \%)$ at $423 \mathrm{~nm}$. This finding is consistent with the devices with the highest Jsc and PCE. Furthermore, the EQE integration against the 1.5 AM G sun spectra results was in good agreement with the measured photocurrents. As can be seen, all the solar cells display fill factor values below 50\% (see Table 2). This issue was independent of the donor/acceptor ratio although, for the best solar cells with a ratio of 1:4 we achieved the highest fill factor values. From these results, it is difficult and too speculative to infer the reasons for the low fill factor. Nevertheless, we believe that the low mobility measured for the "only hole devices" and the unbalanced charge transport between holes and electrons are, definitively important factors that effect a change on the fill factor 
Table 2 Main performance parameters for 1a:PC71BM and 1b:PC71BM devices using different ratios. The values in parenthesis correspond to the highest efficiencies reached for each of the ratio conditions.

\begin{tabular}{ccccc}
\hline Active layer & $\mathrm{V}_{\text {oc }}(\mathrm{V})$ & $J_{s c}\left(\mathrm{~mA} \mathrm{~cm}^{-2}\right)$ & $\mathrm{FF}(\%)$ & PCE (\%) \\
1a:PC71BM (1:4) & $0.79 \pm 0.04$ & $11.03 \pm 0.31$ & $31.4 \pm 0.2$ & $2.73 \pm 0.2(2.86)$ \\
1a:PC71BM (1:3) & $0.87 \pm 0.01$ & $11.48 \pm 0.25$ & $30.2 \pm 0.1$ & $3.01 \pm 0.1(3.04)$ \\
1a:PC71BM (1:2) & $0.85 \pm 0.01$ & $11.36 \pm 0.21$ & $30.8 \pm 0.3$ & $3.01 \pm 0.1(3.05)$ \\
1b:PC71BM (1:4) & $0.80 \pm 0.04$ & $13.2 \pm 0.21$ & $40.1 \pm 0.29$ & $4.24 \pm 0.1(4.35)$ \\
1b:PC71BM (1:3) & $0.82 \pm 0.02$ & $12.45 \pm 0.24$ & $38.5 \pm 0.24$ & $3.91 \pm 0.1(3.98)$ \\
1b:PC71BM (1:2) & $0.84 \pm 0.03$ & $12.12 \pm 0.37$ & $34.7 \pm 0.26$ & $3.55 \pm 0.1(3.63)$
\end{tabular}
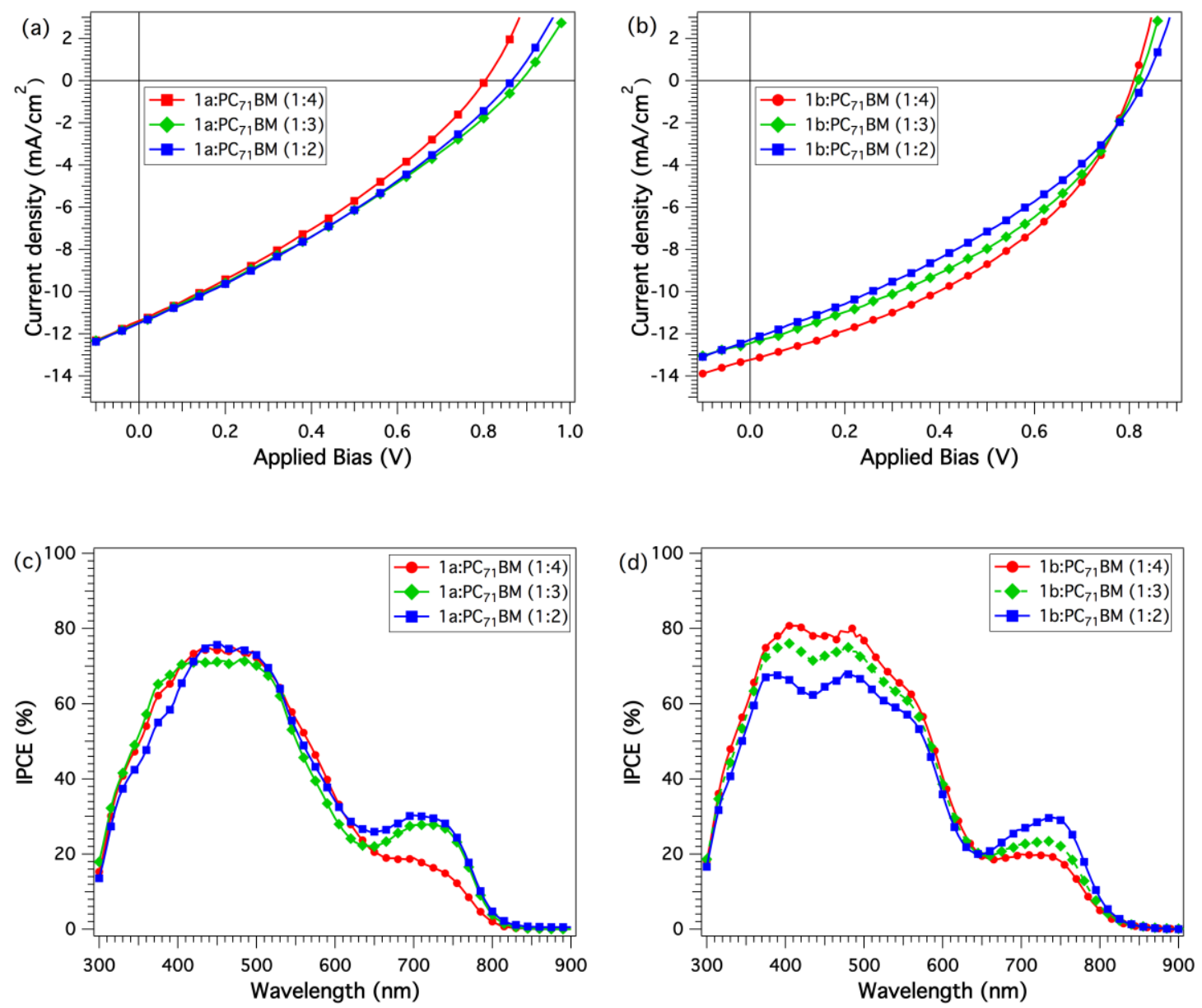
Figure 4 (a) Current density-voltage (J-V) characteristics of 1a:PC71BM devices; (b) 1b:PC71BM devices, both at different ratios; (c) EQE of 1a:PC71BM and (d) EQE of 1b:PC71BM devices.
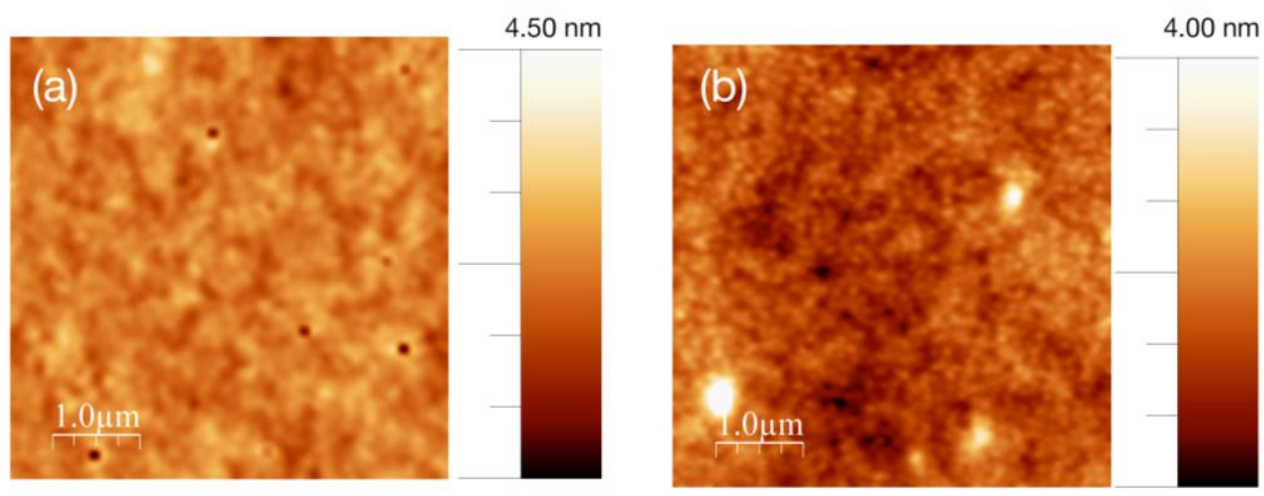

Figure 5. AFM images of (a) 1a:PC71BM and (b) 1b:PC71BM in the most efficient devices.

Once the solar cells had been evaluated, the morphologies of the active layer were characterized by atomic force microscopy (AFM) in tapping mode in order to gain an insight into the differences in device performance, using the best composition for each device, as shown in Figure 5. The surface topographies of the film of the 1b:PC71BM (1:4) blend displays rather uniform nanometer-sized features with a root-mean-square roughness ( $\mathrm{rms}$ ) value of $0.53 \mathrm{~nm}$. In contrast, the blend containing 1a with PC71BM exhibited a coarser topography, with higher rms values of $0.62 \mathrm{~nm}$. The surface of the former is smoother than that of the latter and it also has better-defined morphological features. This is often related to better phase intermixing, which in turn leads to better phase separation and is beneficial for efficient exciton diffusion and charge transport.

The effect that the blend nano-morphology has on the solar cell parameters was analyzed further by measuring the hole carrier mobility in complete devices with the appropriate selective contacts (see Supporting Information). The mobility was calculated using the Space Charge 
Limited Current method (SCLC) as described in the Supporting Information (Figure S19). Values for $\mathbf{1 a}$ and $\mathbf{1 b}$ of $1.25 \pm 0.8 \times 10^{-5} \mathrm{Vcm}^{-2} \mathrm{~s}^{-1}$ and $1.53 \pm 0.3 \times 10^{-5} \mathrm{Vcm}^{-2} \mathrm{~s}^{-1}$, respectively, were obtained. It should be noted that, in contrast to previous publications,[33-40] the effect of the alkyl chains in these molecules on the hole carrier mobility is less critical. Moreover, it was determined that the hole carrier mobility is not responsible for the difference between the two porphyrin-based devices and, more importantly, this physical characteristic is not considered to be a determinant factor for the final device performance.

Finally, the carrier losses were evaluated by measuring the interfacial carrier recombination kinetics as reported previously.[33, 34, 41-48]

The charge extraction of 1a-b is depicted in Figure 6a and was determined by subtracting the contribution of the geometrical capacitance. The total extracted charges are shown in the Supporting Information (Figure S20), where the geometric contribution is indicated by a straight line and the calculated values are 80 and $64 \mathrm{nF} \mathrm{cm}^{-2}$ for $\mathbf{1 a}$ and $\mathbf{1 b}$, respectively. Hence, the charge values shown in Figure $6 \mathrm{~b}$ correspond to the photo-induced charge, which can either be stored at the contacts, in the bulk of the device or both. As can be seen in Figure 6a, there is a shift in the exponential in devices made with 1a and this finding is in good agreement with the 5$10 \mathrm{mV}$ increase in Voc observed in the IV curves.

Moreover, on using $\mathbf{1 b}$ the organic blend is capable of storing more charges at a given photoinduced voltage (the so-called light bias) and, as shown above, can extract these charges more efficiently when compared to 1a. The Photo-Induced Transient Photo-Voltage (PIT-PV) technique was also applied to compare the charge lifetime of devices based on $\mathbf{1 a}$ and $\mathbf{1 b}$. A clear difference can be seen between these two materials. Firstly, 1b clearly has a slower carrier lifetime than 1a. The slower carrier recombination dynamics, in addition to the observed shift in 
the exponential charge density measurement, explain the higher Voc observed for $\mathbf{1 b}$. It is known that the Voc of a solar cell is closely related to the carrier recombination dynamics under illumination. The slower the carrier recombination the higher the Voc for devices with similar charge density.

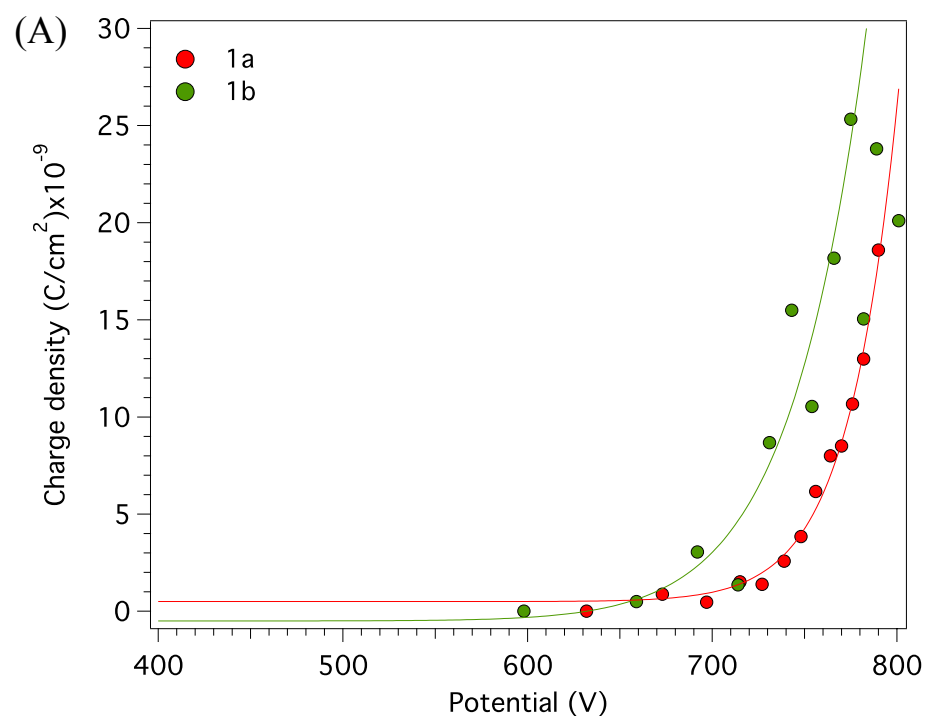




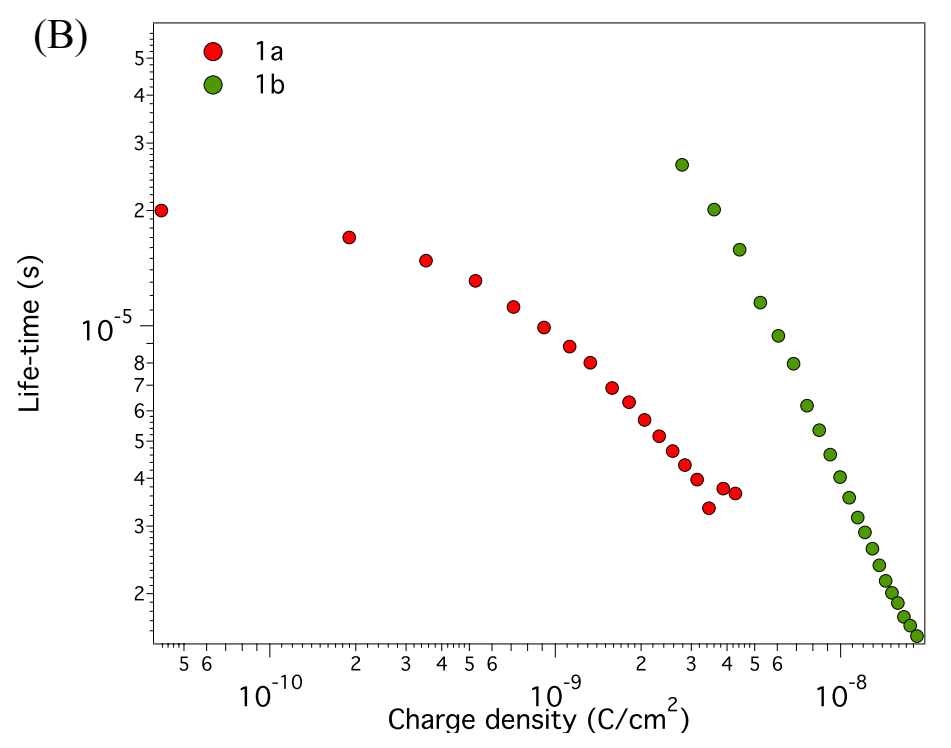

Figure 6. (A) Charge density at different light intensities (light bias) of 1a (red line) and 1b (green line). The charges correspond to the extracted charges under different illumination conditions. (B) The carrier life-time of $\mathbf{1 a}$ (red line) and $\mathbf{1 b}$ (green line) at different charge values.

The results described above indicate that the molecular structure of $\mathbf{1 b}$ favors better film nanomorphology and thus improved charge collection and slower carrier recombination dynamics.

\section{Conclusions}

Two conjugated molecules bearing a Zn-porphyrin, which act as an electron donor, linked by ethynylene units to one or two thienylenevinylene moieties and capped by ethylenerhodanine groups as acceptor units have been synthesized and characterized for solution processed small 
molecule solar cells. The design strategy was based on the incorporation of electron-accepting ethylenerhodanine moieties through the thiophene based bridges, which shift the absorption profiles bathocromically to the NIR due to a more intense intramolecular charge transfer band. Compounds 1a and 1b exhibit excellent light harvesting properties, good thermal stability and have low-lying HOMO levels of -5.36 and $-5.24 \mathrm{eV}$, respectively. Complete SMOSCs were fabricated using 1a and $\mathbf{1 b}$ donors combined with PC71BM as the electron acceptor molecule. Compound $\mathbf{1 b}$ gave a PCE of $4.3 \%$. The EQE measurements are consistent with the Jsc values obtained, with an incident photon-to-current efficiency of $80 \%$ at $430 \mathrm{~nm}$ for the $1 \mathbf{b}$ :PC71BM device with a 1:4 ratio. The hole carrier mobility was also measured and values of $1.25 \pm 0.8 \times 10^{-5}$ $\mathrm{Vcm}^{-2} \mathrm{~s}^{-1}$ and $1.56 \pm 0.4 \times 10^{-5} \mathrm{Vcm}^{-2} \mathrm{~s}^{-1}$ were obtained, respectively. Finally, photo-induced charge extraction and photo-induced transient photo-voltage experiments were carried out in order to determine the origin of the difference in performance between devices based on $\mathbf{1 a}$ and $\mathbf{1 b}$. The PICE showed a shift that mirrored the difference in Voc and very similar distribution of charges versus applied light bias, although $\mathbf{1 b}$ can store more charge at the same voltage. Moreover, the PIT-PV showed a marked difference between the two molecules; In the case of $\mathbf{1 b}$ the carrier lifetime was considerably shorter than that of $\mathbf{1 a}$. Thus, for $\mathbf{1 b}$ the presence of the thiophene groups not only improves the light absorption but also changes the nano-morphology and, hence, the carrier extraction and recombination. This is achieved without a substantial decrease in the device Voc, as expected due to the reduced bandgap of $\mathbf{1 b}$.

\section{Acknowledgements}

Financial support from the Ministry of Science and Innovation of Spain (CTQ2013-48252-P) and Junta de Comunidades de Castilla-La Mancha (PEII-2014-014-P) is gratefully acknowledged. SA thanks the Fundación Carolina for a grant. EP would like to thank ICIQ and ICREA for 
financial support as well as the MINECO projects CTQ2013-47183r and the Severo Ochoa Accreditation (SO-2013-0319). L.E. thanks the Robert A. Welch Foundation for an endowed chair, grant \#AH-0033, the US National Science Foundation, grant DMR-1205302 (PREM Program).

\section{Notes and references}

[1] G. Yu, J. Gao, J.C. Hummelen, F. Wudl, A.J. Heeger, Polymer Photovoltaic Cells: Enhanced Efficiencies via a Network of Internal Donor-Acceptor Heterojunctions, Science, 270 (1995) 1789-1791.

[2] H.-Y. Chen, J. Hou, S. Zhang, Y. Liang, G. Yang, Y. Yang, L. Yu, Y. Wu, G. Li, Polymer solar cells with enhanced open-circuit voltage and efficiency, Nat Photon, 3 (2009) 649-653.

[3] G. Li, R. Zhu, Y. Yang, Polymer solar cells, Nat Photon, 6 (2012) 153-161.

[4] R.F. Service, Outlook Brightens for Plastic Solar Cells, Science, 332 (2011) 293-293.

[5] T. Yang, M. Wang, C. Duan, X. Hu, L. Huang, J. Peng, F. Huang, X. Gong, Inverted polymer solar cells with $8.4 \%$ efficiency by conjugated polyelectrolyte, Energy \& Environmental Science, 5 (2012) 8208-8214.

[6] J. Subbiah, B. Purushothaman, M. Chen, T. Qin, M. Gao, D. Vak, F.H. Scholes, X. Chen, S.E. Watkins, G.J. Wilson, A.B. Holmes, W.W.H. Wong, D.J. Jones, Organic Solar Cells Using a High-Molecular-Weight Benzodithiophene-Benzothiadiazole Copolymer with an Efficiency of 9.4\%, Advanced Materials, 27 (2015) 702-705.

[7] T. Ameri, N. Li, C.J. Brabec, Highly efficient organic tandem solar cells: a follow up review, Energy \& Environmental Science, 6 (2013) 2390-2413.

[8] F.C. Krebs, N. Espinosa, M. Hösel, R.R. Søndergaard, M. Jørgensen, 25th Anniversary Article: Rise to Power - OPV-Based Solar Parks, Advanced Materials, 26 (2014) 29-39.

[9] A.J. Heeger, 25th Anniversary Article: Bulk Heterojunction Solar Cells: Understanding the Mechanism of Operation, Advanced Materials, 26 (2014) 10-28.

[10] C.-C. Chen, W.-H. Chang, K. Yoshimura, K. Ohya, J. You, J. Gao, Z. Hong, Y. Yang, An Efficient Triple-Junction Polymer Solar Cell Having a Power Conversion Efficiency Exceeding 11\%, Advanced Materials, 26 (2014) 5670-5677.

[11] B. Kan, Q. Zhang, M. Li, X. Wan, W. Ni, G. Long, Y. Wang, X. Yang, H. Feng, Y. Chen, Solution-Processed Organic Solar Cells Based on Dialkylthiol-Substituted Benzodithiophene Unit with Efficiency near 10\%, Journal of the American Chemical Society, 136 (2014) 1552915532.

[12] J. Roncali, P. Leriche, P. Blanchard, Molecular Materials for Organic Photovoltaics: Small is Beautiful, Advanced Materials, 26 (2014) 3821-3838.

[13] Y. Liu, J. Zhao, Z. Li, C. Mu, W. Ma, H. Hu, K. Jiang, H. Lin, H. Ade, H. Yan, Aggregation and morphology control enables multiple cases of high-efficiency polymer solar cells, Nat Commun, 5 (2014).

[14] J. Xue, S. Uchida, B.P. Rand, S.R. Forrest, Asymmetric tandem organic photovoltaic cells with hybrid planar-mixed molecular heterojunctions, Applied Physics Letters, 85 (2004) 57575759 . 
[15] V. Steinmann, N.M. Kronenberg, M.R. Lenze, S.M. Graf, D. Hertel, K. Meerholz, H. Bürckstümmer, E.V. Tulyakova, F. Würthner, Simple, Highly Efficient Vacuum-Processed Bulk Heterojunction Solar Cells Based on Merocyanine Dyes, Advanced Energy Materials, 1 (2011) 888-893.

[16] S. Yoo, B. Domercq, B. Kippelen, Efficient thin-film organic solar cells based on pentacene/C60 heterojunctions, Applied Physics Letters, 85 (2004) 5427-5429.

[17] G. Wei, S. Wang, K. Sun, M.E. Thompson, S.R. Forrest, Solvent-Annealed Crystalline Squaraine: PC70BM (1:6) Solar Cells, Advanced Energy Materials, 1 (2011) 184-187.

[18] B. Walker, A.B. Tamayo, X.-D. Dang, P. Zalar, J.H. Seo, A. Garcia, M. Tantiwiwat, T.-Q. Nguyen, Nanoscale Phase Separation and High Photovoltaic Efficiency in Solution-Processed, Small-Molecule Bulk Heterojunction Solar Cells, Advanced Functional Materials, 19 (2009) 3063-3069.

[19] J. Kesters, P. Verstappen, M. Kelchtermans, L. Lutsen, D. Vanderzande, W. Maes, Porphyrin-Based Bulk Heterojunction Organic Photovoltaics: The Rise of the Colors of Life, Advanced Energy Materials, 5 (2015) n/a-n/a.

[20] H. Imahori, T. Umeyama, S. Ito, Large œÄ-Aromatic Molecules as Potential Sensitizers for Highly Efficient Dye-Sensitized Solar Cells, Accounts of Chemical Research, 42 (2009) 18091818 .

[21] L. Li, Y. Huang, J. Peng, Y. Cao, X. Peng, Enhanced performance of solution-processed solar cells based on porphyrin small molecules with a diketopyrrolopyrrole acceptor unit and a pyridine additive, Journal of Materials Chemistry A, 1 (2013) 2144-2150.

[22] H. Qin, L. Li, F. Guo, S. Su, J. Peng, Y. Cao, X. Peng, Solution-processed bulk heterojunction solar cells based on a porphyrin small molecule with $7 \%$ power conversion efficiency, Energy \& Environmental Science, 7 (2014) 1397-1401.

[23] C. Vijay Kumar, L. Cabau, E.N. Koukaras, G.D. Sharma, E. Palomares, Synthesis, optical and electrochemical properties of the A-[small pi]-D-[small pi]-A porphyrin and its application as an electron donor in efficient solution processed bulk heterojunction solar cells, Nanoscale, 7 (2015) 179-189.

[24] J. Rawson, A.C. Stuart, W. You, M.J. Therien, Tailoring Porphyrin-Based Electron Accepting Materials for Organic Photovoltaics, Journal of the American Chemical Society, 136 (2014) 17561-17569.

[25] S. Chen, L. Xiao, X. Zhu, X. Peng, W.-K. Wong, W.-Y. Wong, Solution-processed new porphyrin-based small molecules as electron donors for highly efficient organic photovoltaics, Chemical Communications, 51 (2015) 14439-14442.

[26] H. Wang, L. Xiao, L. Yan, S. Chen, X. Zhu, X. Peng, X. Wang, W.-K. Wong, W.-Y. Wong, Structural engineering of porphyrin-based small molecules as donors for efficient organic solar cells, Chemical Science, 7 (2016) 4301-4307.

[27] K. Gao, L. Li, T. Lai, L. Xiao, Y. Huang, F. Huang, J. Peng, Y. Cao, F. Liu, T.P. Russell, R.A.J. Janssen, X. Peng, Deep Absorbing Porphyrin Small Molecule for High-Performance Organic Solar Cells with Very Low Energy Losses, Journal of the American Chemical Society, 137 (2015) 7282-7285.

[28] A. Yella, H.-W. Lee, H.N. Tsao, C. Yi, A.K. Chandiran, M.K. Nazeeruddin, E.W.-G. Diau, C.-Y. Yeh, S.M. Zakeeruddin, M. Grل§tzel, Porphyrin-Sensitized Solar Cells with Cobalt (II/III), ÄiBased Redox Electrolyte Exceed 12 Percent Efficiency, Science, 334 (2011) 629-634. 
[29] S. Arrechea, A.n. Molina-Ontoria, A. Aljarilla, P. de la Cruz, F. Langa, L. Echegoyen, New acceptor,p-porphyrin,p-acceptor systems for solution-processed small molecule organic solar cells, Dyes and Pigments, 121 (2015) 109-117.

[30] A. Cravino, Origin of the open circuit voltage of donor-acceptor solar cells: Do polaronic energy levels play a role?, Applied Physics Letters, 91 (2007) 243502.

[31] G. Dennler, M.C. Scharber, C.J. Brabec, Polymer-Fullerene Bulk-Heterojunction Solar Cells, Advanced Materials, 21 (2009) 1323-1338.

[32] M.C. Scharber, D. Mühlbacher, M. Koppe, P. Denk, C. Waldauf, A.J. Heeger, C.J. Brabec, Design Rules for Donors in Bulk-Heterojunction Solar Cells-Towards $10 \%$ EnergyConversion Efficiency, Advanced Materials, 18 (2006) 789-794.

[33] N.F. Montcada, L. Cabau, C.V. Kumar, W. Cambarau, E. Palomares, Indoline as electron donor unit in ,ÄúPush,ÄiPull, Äù organic small molecules for solution processed organic solar cells: Effect of the molecular œÄ-bridge on device efficiency, Organic Electronics, 20 (2015) $15-23$.

[34] N.F. Montcada, R. Dominguez, B. Pelado, P.d.l. Cruz, E. Palomares, A. Viterisi, F. Langa, Correction: High photocurrent in oligo-thienylenevinylene-based small molecule solar cells with 4.9\% solar-to-electrical energy conversion, Journal of Materials Chemistry A, 3 (2015) 1209712097.

[35] G.F.A. Dibb, F.C. Jamieson, A. Maurano, J. Nelson, J.R. Durrant, Limits on the Fill Factor in Organic Photovoltaics: Distinguishing Nongeminate and Geminate Recombination Mechanisms, The Journal of Physical Chemistry Letters, 4 (2013) 803-808.

[36] T. Kirchartz, T. Agostinelli, M. Campoy-Quiles, W. Gong, J. Nelson, Understanding the Thickness-Dependent Performance of Organic Bulk Heterojunction Solar Cells: The Influence of Mobility, Lifetime, and Space Charge, The Journal of Physical Chemistry Letters, 3 (2012) 3470-3475.

[37] B.-G. Kim, X. Ma, C. Chen, Y. Ie, E.W. Coir, H. Hashemi, Y. Aso, P.F. Green, J. Kieffer, J. Kim, Energy Level Modulation of HOMO, LUMO, and Band-Gap in Conjugated Polymers for Organic Photovoltaic Applications, Advanced Functional Materials, 23 (2013) 439-445.

[38] Y. Li, Molecular Design of Photovoltaic Materials for Polymer Solar Cells: Toward Suitable Electronic Energy Levels and Broad Absorption, Accounts of Chemical Research, 45 (2012) 723-733.

[39] J. Zhou, X. Wan, Y. Liu, Y. Zuo, Z. Li, G. He, G. Long, W. Ni, C. Li, X. Su, Y. Chen, Small Molecules Based on Benzo[1,2-b:4,5-b, $\ddot{A} \leq]$ dithiophene Unit for High-Performance Solution-Processed Organic Solar Cells, Journal of the American Chemical Society, 134 (2012) 16345-16351.

[40] A. Mishra, P. Bäuerle, Small Molecule Organic Semiconductors on the Move: Promises for Future Solar Energy Technology, Angewandte Chemie International Edition, 51 (2012) 20202067.

[41] C.G. Shuttle, A. Maurano, R. Hamilton, B. O,ÄôRegan, J.C. de Mello, J.R. Durrant, Charge extraction analysis of charge carrier densities in a polythiophene/fullerene solar cell: Analysis of the origin of the device dark current, Applied Physics Letters, 93 (2008) 183501.

[42] A. Sánchez-Díaz, M. Izquierdo, S. Filippone, N. Martin, E. Palomares, The Origin of the High Voltage in DPM12/P3HT Organic Solar Cells, Advanced Functional Materials, 20 (2010) 2695-2700. 
[43] A. Sánchez-Díaz, R. Pacios, U. Muñecas, T. Torres, E. Palomares, Charge transfer reactions in near IR absorbing small molecule solution processed organic bulk-heterojunction solar, Organic Electronics, 12 (2011) 329-335.

[44] A. Guerrero, N.F. Montcada, J. Ajuria, I. Etxebarria, R. Pacios, G. Garcia-Belmonte, E. Palomares, Charge carrier transport and contact selectivity limit the operation of PTB7-based organic solar cells of varying active layer thickness, Journal of Materials Chemistry A, 1 (2013) $12345-12354$.

[45] N.r.F. Montcada, B. Pelado, A. Viterisi, J. Albero, J. Coro, P.d.l. Cruz, F. Langa, E. Palomares, High open circuit voltage in efficient thiophene-based small molecule solution processed organic solar cells, Organic Electronics, 14 (2013) 2826-2832.

[46] D. Fernandez, A. Viterisi, J.W. Ryan, F. Gispert-Guirado, S. Vidal, S. Filippone, N. Martin, E. Palomares, Small molecule BHJ solar cells based on DPP(TBFu)2 and diphenylmethanofullerenes (DPM): linking morphology, transport, recombination and crystallinity, Nanoscale, 6 (2014) 5871-5878.

[47] J.W. Ryan, T. Kirchartz, A.1. Viterisi, J. Nelson, E. Palomares, Understanding the Effect of Donor Layer Thickness and a MoO3 Hole Transport Layer on the Open-Circuit Voltage in Squaraine/C60 Bilayer Solar Cells, The Journal of Physical Chemistry C, 117 (2013) 1986619874.

[48] A. Sánchez-Díaz, L. Burtone, M. Riede, E. Palomares, Measurements of Efficiency Losses in Blend and Bilayer-Type Zinc Phthalocyanine/C60 High-Vacuum-Processed Organic Solar Cells, The Journal of Physical Chemistry C, 116 (2012) 16384-16390. 
Graphical Abstract

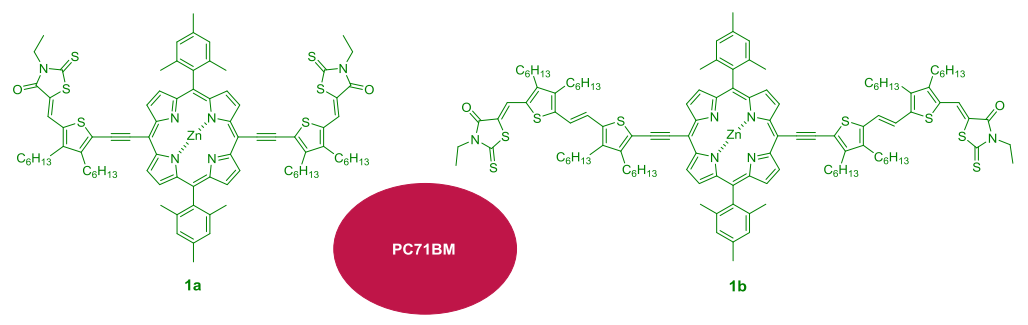

